\title{
Influence of Cardiorespiratory Fitness and Drinking Habits on Total Cancer Mortality: A Cohort Study of Japanese Man
}

\author{
Munehiro Matsushita ${ }^{1,2}$, Motohiko Miyachi ${ }^{1}$, Ryoko Kawakami ${ }^{1,2}$, Takashi Okamoto ${ }^{3}$, Koji Tsukamoto ${ }^{3}$, \\ Yoshio Nakata ${ }^{4}$, Takashi Arao ${ }^{5}$ and Susumu S. Sawada ${ }^{1}$ \\ 1 独立行政法人国立健康・栄養研究所健康增進研究部， ₹ 162-8636 東京都新宿区戸山1-23-1 (Department of Health Pro- \\ motion and Exercise, National Institute of Health and Nutrition, 1-23-1 Toyama, Shinjuku-ku, Tokyo 162-8636, Japan) \\ ${ }^{2}$ 早稲田大学大学院スポーツ科学研究科，７369-1192 埼玉県所沢市三ヶ島 2-579-15 (Graduate School of Sports Sciences, \\ Waseda university, 2-579-15 Mikajima, Tokorozawa-city, Saitama 369-1192, Japan) \\ 3 東京ガス株式会社安全健康・福利室， ₹ 105-8527 東京都港区海岸 1-5-20 (Department of Safety and Health, Tokyo Gas \\ Co. Ltd., 1-5-20 Kaigan, Minato-ku, Tokyo 105-8527, Japan) \\ 4 筑波大学医学医療系, ॠ305-8575 茨城県つくば市天王台1-1-1 (Faculty of Medicine, University of Tsukuba, 1-1-1 Ten- \\ nodai, Tsukuba, Ibaraki 305-8575, Japan) \\ 5 早稲田大学スポーツ科学学術院，７369-1192 埼玉県所沢市三ヶ島 2-579-15 (Faculty of Sports Sciences, Waseda university, \\ 2-579-15 Mikajima, Tokorozawa-city, Saitama 369-1192, Japan)
}

Received: May 27, 2013 / Accepted: August 13, 2013

\begin{abstract}
Several studies have shown that low cardiorespiratory fitness (CRF) or heavy alcohol consumption is risks of total or certain types of cancer death. However, the combined influence of $\mathrm{CRF}$ and drinking habits on total cancer mortality is not clear. The purpose of this study was to investigate the joint effect of CRF and drinking habits on total cancer mortality among Japanese men. We evaluated the CRF and drinking habits on risk of total cancer mortality in 8,760 Japanese men (age: 19-59 yr) who were given a submaximal exercise test, a medical examination test, and questionnaires on their health habits. CRF was measured using a cycle ergometer test, and the men were classified into two categories by CRF levels based on the reference value of CRF (R-CRF) in "Physical Activity Reference for Health Promotion 2013" (Under R-CRF and Over R-CRF). Also, the men were assigned to Non Drinking, Moderate Drinking, and Heavy Drinking categories. There were 178 cancer deaths during the 20yr follow-up period. Relative risk and $95 \%$ confidence intervals for total cancer mortality were obtained using the Cox proportional hazards model while adjusting for age, body mass index, systolic blood pressure, and smoking habits. Using the Under R-CRF \& Heavy Drinking group as reference, the relative risk and $95 \%$ confidence intervals were $0.37(0.16-0.85)$ for the Over R-CRF \& Non Drinking group. This result suggests that Japanese male with a high CRF and a low drinking habit have a lower risk of total cancer mortality.
\end{abstract}

Jpn J Phys Fitness Sports Med, 62(5): 375-381 (2013)

Keywords : physical fitness, respiratory function tests, alcohol drinking, neoplasms, cohort study

\section{緒言}

がんは世界全体における主要な死因の1つである。 2012年世界保健統計では，2008年における全死亡のうち 全がんによる死亡者数は 760 万人 $(21 \%)$ であり, 2030 年には 1,700 万人に増加すると試算されており1，がん予 防は世界的な健康課題の 1 つであると考えられる.
全身持久力は全がん死亡の関連因子であるとの報告が 多数ある。たとえば，欧米人を対象としたコホート研究 では，全身持久力と，すべての部位，あるいは特定の部 位におけるがんの罹患，もしくは死亡との関連がいくつ か報告されている ${ }^{2-12)}$. 同様に，日本人を対象とした研 究においても，全身持久力と全がん死亡のリスクの間に 負の量反応関係が認められることが報告されている13). 
以上のように，全身持久力と全がん死亡の関連を報告す る研究は蓄積されつつある。

また飲酒は，世界各国の大規模観察研究を対象とした システマティックレビューにより, 全がん死亡に扮け る危険因子の 1 つであると報告されている ${ }^{14)}$ ．また，わ が国の大規模コホート研究のみを対象としたシステマ ティックレビューに扔いても, 飲酒は全がん死亡との関 連が認められた ${ }^{15)}$ 。そのため, 飲酒と全がん死亡との関 連は確実とされている16).

がん化のメカニズムの1つに, 高インスリン血症によ る肝臓でのインスリン様成長因子 1 の合成促進が関与し, がん細胞の増殖を促進する可能性が考えられている ${ }^{17)}$. インスリンを介したがん化のメカニズムには，インスリ ン抵抗性に影響を与える身体活動 ${ }^{18)}$ に関する生活習慣状 況を反映すると考えられる全身持久力や飲酒習慣 ${ }^{199}$ が関 連することが考えられる。したがって，全身持久力と飲 酒習慣の組み合わせががん死亡に与える影響を明らかに することは，全身持久力ががん死亡に予防的に機能する メカニズム解明に向けた示唆を与え, さらにがん予防へ の効果的な生活習慣の提案の幅を広げるものであると考 えられる. そこで本研究は, 日本人の男性労働者を対象 にして，全がん死亡に対する全身持久力と飲酒習慣の組 み合わせの影響を検討することを目的とした。

\section{方 法}

対象者 本研究の対象者は, 東京ガス株式会社に扔いて 1982年から1988年の間に定期健康診断を受診した19歳か ら59歳の男性 11,978 人である. 女性については対象者数 が少ないことから本研究の対象に含めなかった，定期健 康診断に打いて, がん, 循環器疾患, 糖尿病, 消化器疾 患, 結核に罹患している者 $(\mathrm{n}=1,162)$ は, 対象から除外 された。また, 問診により喘息, 肝疾患, 腎疾患, 骨折, 腰椎ねん挫, 腰痛, 神経痛について確認した. 上記の疾 患や障害に該当した者 $(n=1,777)$ は, 後述する最大下 運動負荷テストを適切に実施できない可能性があるた め, 対象から除外した，さらに，顕在化していないがん が低体重をもたらしているという可能性を排除するため に, BMI (体重 $[\mathrm{kg}] /$ 身長 $\left.[\mathrm{m}]^{2}\right)$ が18.5未満の者 $(\mathrm{n}=279)$ を対象から除外した. 以上 3 つの除外基準を設けた結果, 最終的に 8,760 人の男性が本研究の対象者となった.

本研究は独立行政法人国立健康・栄養研究所に打ける 倫理審査委員会の承認を受けて実施された。

健康診断 対象者は労働安全衛生法に基づき定期健康診 断を毎年受診している. 健康診断の結果から身長, 体重, 安静時の収縮期血圧を解析に用いた。身長, 体重の測定 結果から, BMIを求め, 体格の指数とした。安静時血圧 の測定は椅子座位で自動血圧計を用いて測定した.また,
自己記入式質問票を用いて飲酒習慣, 喫煙習慣を確認し た。飲酒習慣については，1 日当たりの飲酒量を「非飲 酒もしくはほとんど飲まない」,「日本酒 1合(ウイスキー ダブル 1 杯, ビール大 1 本) 程度」,「日本酒 2 合（ウイ スキーダブル 2 杯, ビール大 2 本) 程度」,「日本酒 3 合 (ウ イスキーダブル 3 杯, ビール大 3 本) 程度」,「日本酒 4 合（ウイスキーダブル 4 杯，ビール大 4 本）以上」の 5 段階で確認した。また，喫煙習慣については，1日当た りの契煙本数を,「0本（以前から全く吸わない」，「0 本 ( 1 年以上前にやめた) 」, $「 0$ 本 ( 1 年以内にやめた) 」, 「1-20本」,「21-40本」,「41本以上」の 6 段階で確認した。

全身持久力の測定 全身持久力の指標として推定最大酸 素摂取量を用いた。推定最大酸素摂取量は, 自転車エル ゴメータ（モナーク社製，スウェーデン）を用いた最大 下運動負荷テストにより測定した，運動負荷テストは各 段階 4 分間で最大 3 段階から構成されており, 段階が進 むにつれ負荷を漸増する試験である。試験開始時の負荷 は19-29歳, 30-39歳, 40-49歳, 50-59歳に対し, それぞ れ600kpm，525kpm，450kpm，375kpmを与えた。心拍 数は心電図に扔けるR-R間隔により測定した。目標心拍 数は年齢から推定した最大心拍数（220-年齢）の $85 \%$ に設定した，運動負荷は，目標心拍数に到達するまで,

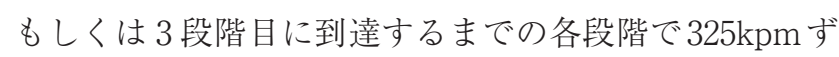
つ増加した，各対象者における最終段階の最後の 1 分間 から得られた心拍数から ÅstrandとRyhmingのノモグラ $\Delta^{20)}$ とÅstrandの年齢補正係数 ${ }^{21)}$ を用いて最大酸素摂取 量を推定した.

対象者の追跡対象者は2003年 6 月 30 日まで追跡され， 追跡期間中のがん死亡の有無が確認された。在職者の死 亡については, 人事情報をもとに，医療スタッフが死亡 者の所属する職場総務担当者に対する電話聞き取り調查 によって死因を確認した，退職後の死亡については，退 職者で組織された会の事務局による家族に対する電話聞 き取り調査によって死因を確認した，対象者が追跡期間 中に死亡した場合や退職等によって追跡不能となった場 合, 打ち切りデータ (censored date) として取り扱った。

解析方法 全身持久力は, 「健康づくりのための身体活 動基準 2013」22)の男性における年代別の最大酸素摂量の 基準值（18-39歳：11.0METs, 40-59歳：10.0METs）を 用い 2 群（体力基準值以上群, 体力基準值未満群）に分 類した。飲酒習慣は, 先行研究 23,24$)$ を参考に, 「非飲酒 もしくはほとんど飲まない」と回答した群を「非飲酒群」, 日本酒 1 合 -2 合程度と回答した群を「少量飲酒群（ア ルコール 45g/日以下)」, 日本酒 3 合以上と回答した群を $「$ 多量飲酒群 $(46 \mathrm{~g} /$ 日以上)」と定義した。また，喫煙習 
慣は,「 0 本と回答した群」,「1-20本と回答した群」,「20 本以上と回答した群」の 3 群に分類した.

本研究では対象者数が少ないことからすべての部位に おけるがんを対象に解析し，部位別のがんを対象とした 解析はおこなわなかった。脳腫瘍や白血病などの特殊な がんよる死亡についても全がん死亡に含めた．全身持久 力および飲酒習慣が全がん死亡にどのような影響を及ぼ しているか検討するためにCoxの比例ハザードモデルを 使用した. 全身持久力 ( 2 群)に扔いては「体力基準未満群」 を, 飲酒習慣 (3群) に拈いては「多量飲酒群」を基準 に, 他の群の全がん死亡のハザード比（相対危険度）お よび $95 \%$ 信頼区間を求めた。全身持久力の評価におい ては年齢 (連続数), BMI (連続数), 収縮期血圧 (連続数), 喫煙習慣（3群），飲酒習慣（3群）を，飲酒習慣の評価に おいては年齢 (連続数), BMI (連続数), 収縮期血圧 (連 続数), 喫煙習慣 ( 3 群), 全身持久力 (2群) を共変量と してモデルに投入して調整した。 また，全身持久力と飲 酒習慣の組み合わせの影響を検討するためにそれぞれの 群を組み合わせ，合計 6 群を設定した，全がん死亡のリ スクが最も高いと考えられる「体力基準值未満\&多量飲 酒群」を基準にして, 他の 5 群の全がん死亡の相対危険 度および95\%信頼区間を求めた。その際, 年齢 (連続数), BMI (連続数), 収縮期血圧 (連続数), 喫煙習慣 (3 群) を共変量としてモデルに投入した，さらに，全身持久力 と飲酒習慣の交互作用を検討するために, 全がん死亡に 対し最も予防的に作用することが期待される「体力基準 值以上\&非飲酒群」の調整済みハザード比を，「体力基準 值以上\&非飲酒」以外の群を基準として算出した。なお， 共変量として, 年齢 (連続数), BMI (連続数), 収縮期 血圧 (連続数), 喫煙習慣 (3 群), 全身持久力 (2 群), 飲 酒習慣（3群）をモデルに投入した。

統計解析にはIBM SPSS Statistics Version 19（IBM Japan, Tokyo, Japan）を使用した.

\section{結果}

対象者の特徵 追跡開始時点に扔ける対象者の年齢の中
央値は35歳であった（範囲：19-59歳）。平均追跡期間は 20.2年（範囲：15-253ケ月）であり，追跡期間中，178人 ががんにより死亡した。なお，がん死亡の部位では，肺 がん (47人), 胃がん (34人), 肝がん (22人), 大腸がん (18 人), 食道がん（12人), その他（45人）を含んでいた.

全身持久力と飲酒習慣の組み合わせで設定された 6 群 の追跡開始時点における身体的特徵をTable 1 に示した。 「体力基準值以上群」は「体力基準值未満群」と比較して 若く,BMIは,「体力基準值以上群」が「体力基準値未満群」 と比較して低かった。収縮期血圧と拡張期血圧について も，「体力基準值以上群」は「体力基準值未満群」と比 較して低い值を示した。喫煙率は,「少量飲酒群」、「非 飲酒群」「多量飲酒群」の順に高い值を示していた。

全がん死亡に対する全身持久力および飲酒習慣の相対危 険度 全がん死亡に対する全身持久力および飲酒習慣の 相対危険度をTable 2 に示した，全身持久力に执いては， 「体力基準值以上群」は「体力基準值未満群」と比較して, 全がん死亡の相対危険度が有意に低いことが認められ た。しかし，飲酒習慣に扔いては全がん死亡との有意な 関連が認められなかった。

\section{全がん死亡に対する全身持久力および飲酒習慣の組み合} わせの影響 全身持久力と飲酒習慣の組み合わせで設 定した 6 群別にみた全がん死亡の相対危険度を Table 3 に示した。「体力基準值未満\&多量飲酒群」と比較して, 他の 5 群はいずれも低い相対危険度を示していたが，統 計学的に有意に低い相対危険度は「体力基準值以上\&非 飲酒群」においてのみ認められた。本解析に加えて, 顕 在化していないがんが全身持久力や飲酒量の低下をもた らす可能性があることから追跡開始 5 年未満にがんで死 亡した人を除いて同様の解析を行ったが，この関連は有 意なままであった（相対危険度：0.38［95\%信頼区間： 0.16-0.87])。また，同じ飲酒習慣のカテゴリで比較した 場合,いずれの群も「体力基準值未満群」と比較して「体 力基準值以上群」は低い相対危険度を示していたが，そ

Table 1. Baseline characteristics of participants according to cardiorespiratory fitness levels and drinking habits.

\begin{tabular}{|c|c|c|c|c|c|c|c|c|}
\hline $\begin{array}{l}\text { Cardiorespiratory } \\
\text { fitness levels }\end{array}$ & Drinking habits & $\mathrm{N}$ & $\operatorname{Age}^{1)}(\mathrm{yr})$ & $\operatorname{METs}^{2,3)}$ & $\begin{array}{l}\text { Body Mass } \\
\text { Index }{ }^{2} \\
(\mathrm{~kg} / \mathrm{m} 2) \\
\end{array}$ & $\begin{array}{c}\text { Systoloic Blood } \\
\text { Pressure }^{2)} \\
(\mathrm{mmHg}) \\
\end{array}$ & $\begin{array}{c}\text { Blood } \\
\text { Pressure }^{2)} \\
(\mathrm{mmHg}) \\
\end{array}$ & $\begin{array}{c}\text { Smokers } \\
(\%)\end{array}$ \\
\hline Under R-CRF & Heavy & 422 & 37 & $9.1 \pm 1.1$ & $23.8 \pm 2.4$ & $127.2 \pm 12.2$ & $77.9 \pm 9.6$ & 34.6 \\
\hline Under R-CRF & Moderate & 3,290 & 36 & $9.3 \pm 1.1$ & $23.4 \pm 2.4$ & $126.2 \pm 11.8$ & $75.8 \pm 10.3$ & 47.5 \\
\hline Under R-CRF & Non or Not-daily & 1,316 & 36 & $9.2 \pm 1.1$ & $23.4 \pm 2.6$ & $124.2 \pm 12.2$ & $73.6 \pm 10.3$ & 40.4 \\
\hline Over R-CRF & Heavy & 202 & 33 & $12.1 \pm 1.5$ & $22.5 \pm 2.3$ & $124.6 \pm 11.8$ & $72.7 \pm 11.1$ & 41.6 \\
\hline Over R-CRF & Moderate & 2,480 & 32 & $12.3 \pm 1.5$ & $22.0 \pm 2.0$ & $123.2 \pm 12.0$ & $71.8 \pm 10.8$ & 50.4 \\
\hline Over R-CRF & Non or Not-daily & 1,050 & 31 & $12.3 \pm 1.5$ & $21.7 \pm 2.0$ & $120.9 \pm 11.9$ & $69.2 \pm 10.6$ & 46.5 \\
\hline & 8,760 & 35 & $10.5 \pm 2.0$ & $22.8 \pm 2.4$ & $124.4 \pm 12.1$ & $73.6 \pm 10.8$ & 46.4 \\
\hline
\end{tabular}

1) Median, 2) Mean $\pm \mathrm{SD}, 3) 1 \mathrm{MET}=3.5 \mathrm{ml} / \mathrm{kg} / \mathrm{min}$

Under R-CRF: under the reference value of cardiorespiratory fitness level, Over R-CRF: over the reference value of cardiorespiratory fitness level. 
Table 2. Multivariable-adjusted hazard ratios for cancer mortality by cardiorespiratory fitness levels and drinking habits at baseline.

\begin{tabular}{|c|c|c|c|c|c|c|c|}
\hline & $\mathrm{N}$ & Man-years & $\begin{array}{c}\text { No. of } \\
\text { cancer death }\end{array}$ & $\begin{array}{c}\text { Cancer death } \\
\text { per } 10,000 \\
\text { man-years }\end{array}$ & $\begin{array}{c}\text { Multivariable- } \\
\text { adjusted } \\
\text { hazard ratio }\end{array}$ & $95 \% \mathrm{CI}$ & $P$ value \\
\hline \multicolumn{8}{|l|}{ Cardiorespiratory fitness levels } \\
\hline Under R-CRF & 5,028 & 101,333 & 127 & 12.5 & $1.00^{1)}$ & & \\
\hline Over R-CRF & 3,732 & 75,402 & 51 & 6.8 & 0.68 & $0.48-0.95$ & 0.02 \\
\hline \multicolumn{8}{|l|}{ Drinking habits } \\
\hline Heavy & 624 & 12,452 & 17 & 13.7 & $1.00^{2)}$ & & \\
\hline Moderate & 5,770 & 116,898 & 109 & 9.3 & 0.69 & $0.41-1.16$ & 0.16 \\
\hline Non or Not-daily & 2,366 & 47,386 & 52 & 11.0 & 0.77 & $0.44-1.34$ & 0.36 \\
\hline & & & & & for trend $=0.77$ & & \\
\hline
\end{tabular}

1) Adjusted for age, body mass index, systoloic blood pressure, smoking, drinking habit

2) Adjusted for age, body mass index, systoloic blood pressure, smoking, cardiorespiratory fitness level

Table 3. Multivariable-adjusted hazard ratios for cancer mortality according to combined cardiorespiratory fitness levels and drinking habits at baseline.

\begin{tabular}{|c|c|c|c|c|c|c|c|c|}
\hline $\begin{array}{l}\text { Cardiorespiratory } \\
\text { fitness levels }\end{array}$ & Drinking habits & $\mathrm{N}$ & Man-years & $\begin{array}{c}\text { No. of } \\
\text { cancer deaths }\end{array}$ & $\begin{array}{c}\text { Cancer death } \\
\text { per } 10,000 \\
\text { man-years }\end{array}$ & $\begin{array}{c}\text { Multivariable } \\
\text {-adjusted } \\
\text { hazard ratio }\end{array}$ & $95 \% \mathrm{CI}$ & $\mathrm{P}$ value \\
\hline Under R-CRF & Heavy & 422 & 8,435 & 13 & 15.4 & $1.00^{1)}$ & & \\
\hline Under R-CRF & Moderate & 3,290 & 66,563 & 72 & 10.8 & 0.70 & $0.39-1.27$ & 0.24 \\
\hline Under R-CRF & Non or Not-daily & 1,316 & 26,336 & 42 & 15.9 & 0.94 & $0.50-1.75$ & 0.84 \\
\hline Over R-CRF & Heavy & 202 & 4,018 & 4 & 10.0 & 0.94 & $0.30-2.88$ & 0.91 \\
\hline Over R-CRF & Moderate & 2,480 & 50,335 & 37 & 7.4 & 0.56 & $0.30-1.07$ & 0.08 \\
\hline Over R-CRF & Non or Not-daily & 1,050 & 21,050 & 10 & 4.8 & 0.37 & $0.16-0.85$ & 0.02 \\
\hline
\end{tabular}

1) Adjusted for age, body mass index, systoloic blood pressure, smoking habit

Under R-CRF: under the reference value of cardiorespiratory fitness level, Over R-CRF: over the reference value of cardiorespiratory fitness level.

の差は「多量飲酒群」と「少量飲酒群」では小さく,「非 飲酒群」において顕著であった。また，交互作用項の八 ザード比，すなわち「体力基準值以上\&非飲酒群」以外 の群を基準とした場合の「体力基準值以上\&非飲酒群」 の調整済みハザード比（年齢，BMI，収縮期血圧，喫煙 習慣, METs, 飲酒習慣により調整）は， 0.48 (95\%信頼 区間：0.22-1.06, $\mathrm{p}=0.07)$ であり, 統計的に有意な交互 作用は認められなかった。

\section{考察}

本研究は, 日本人の男性労働者を追跡調査し, 全がん 死亡に対する全身持久力と飲酒習慣の独立した効果およ び組み合わせの影響を検討した。そその結果，全身持久力 について「体力基準值以上群」は，「体力基準值未満群」 と比較して, 全がん死亡の相対危険度が有意に低かった。 一方, 飲酒習慣については「多量飲酒群」と比較して少 量あるいは非飲酒群の全がん死亡の相対危険度が低かっ たが, 統計学的有意性は確認できなかった。また,「体力 基準值未満\&多量飲酒群」を基準にした場合,「体力基準 值以上\&非飲酒群」は有意に低い相対危険度を示してい たことから，全身持久力が基準值より低く，多量に飲酒 する人は全がん死亡のリスクが高い可能性が示された。
全身持久カとがん死亡 これまでに実施された全身持久 力とがん死亡の関係を調査したコホート研究は, 低い全 身持久力がすべての部位，あるいは特定の部位における がん死亡のリスクファクターであることを報告している-13).

本研究では「健康づくりのための身体活動基準 2013」22) に打ける全身持久力の基準值を用いて全身持久力を 2 群 に分けた結果,「体力基準值以上群」は全がん死亡のリ スクが低いことが示された。この結果は先行研究の結果 を支持するものである，さらに「健康づくりのための身 体活動基準2013」を用いた分類が全がん死亡の予測因 子のひとつになりうる可能性が示唆された。

飲酒習慣とがん死亡 これまでの先行研究によれば，全 がんと 1 日あたりの飲酒量は J カーブの関係にあると報 告されている. Jinら ${ }^{14)}$ は, 18本の論文をシステマティッ クレビューし, 少量の飲酒 (アルコール $12.5 \mathrm{~g} /$ 日未満) が全がん死亡のリスクを下げ，それ以上の飲酒量ではリ スクを上げることを報告している。また，日本人を対 象にした大規模コホート研究の報告では, Inoueら ${ }^{25}$ は, 週あたりアルコール摂取量と全がんの死亡のリスクに量 反応関係があることを報告している。これらの研究は多 量飲酒が全がん死亡のリスクファクターであることを示 している. 
本研究においても「多量飲酒群」と比較して少量およ び非飲酒群の全がん死亡の相対危険度はいずれも低い值 を示しており（0.69 および $0.77 ）$, 多量飲酒が全がん死亡 のリスクファクターである可能性を示唆していたが, 統 計学的有意性は認められなかった。 その理由としては, 本研究に扔ける多量飲酒者は全体の $7.1 \%(\mathrm{n}=624)$ と 少なく, 統計的な検出力が十分ではなかったことが考元 られる。

\section{がん死亡に対する全身持久力と飲酒習慣の組み合わせの}

影響 本研究に抏いて, 全がん死亡に対する全身持久力 と飲酒習慣に統計的に有意な交互作用は認められなかっ た。笛の原因として,「体力基準值以上\&非飲酒群」の 人数が全体の $12.0 \%(\mathrm{n}=1,050)$ と少なく, 統計的な検出 力が十分ではなかったことが考えられる.

一方，「体力基準值未満群」を基準とした場合の「体 力基準值以上群」の相対危険度は 0.68 ,「多量飲酒群」を

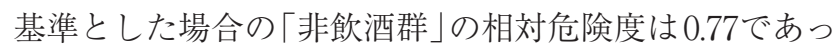
た。このことから，積算モデルによって期待される「体

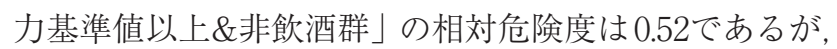
実際の「体力基準值以上\&非飲酒群」の相対危険度は 0.37 であった，このことから，サンプルサイズを増やし，統 計的検出力を高めることで, 全身持久力と飲酒習慣の組 み合わせは全がん死亡に対し，有意な交互作用が認めら れる可能性があると考えられた。

交互作用が認められた場合に考えられる全身持久力と 飲酒習慣が全がん死亡に及ぼす交互作用の機序として, 飲酒による糖質摂取と，身体活動によるインスリン抵抗 性の改善が考えられる。アルコルには，インスリンの 分泌を促す作用がある ${ }^{26)}$. 一方，アルコールを多量に摂 取した場合では，インスリン感受性が低下することが報 告されている ${ }^{19)}$ 。すなわち,「多量飲酒群」ではインス リン抵抗性が生じやすく, 過剩にインスリンが分泌され ることが考えられる。過剩に分泌されたインスリンは, インスリンによる細胞増殖作用，または高インスリン血 症による肝臟でのインスリン様成長因子 1 （insulin-like

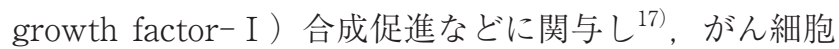
の増殖を促進する可能性が考えられる，身体活動はこの ようながん化のメカニズムに関わるインスリン抵抗性を 改善することが報告されている ${ }^{18)}$. 本研究で指標とした 全身持久力は身体活動量の客観的な指標と考元られて いる27). したがって,「体力基準值以上\&非飲酒群」は, 飲酒をしないことでインスリン分泌を適正に保ち，さら に身体活動によりインスリン抵抗性を正常に保つ $2 つ の$ 作用により，がん死亡のリスクを低くするが，飲酒習慣 があると身体活動による改善効果を相殺するため, 効果 の生じ方に差が生じたものと推察される.
本研究の課題 本研究にはいくつかの課題が存在する. まず飲酒習慣と全がん死亡の関倸において, 統計学的に 有意な相対危険度が観察されなかった。これは，本研究 は先行研究と比較して観察人年が少なく, 統計学的な検 出力が不足していたことが原因と考えられる。 また, 観 察人年が少ないために，がんの部位別に解析をすること ができなかったことも本研究の課題である。また，本研 究に扔ける飲酒習慣の把握には簡便な自己記入式質問票 を用いており, その調查方法の妥当性・信頼性が確認さ れていないことも, 研究の限界である。 さらに，本研究 に扔ける飲酒習慣の評価では, 過去の飲酒習慣について は考慮されて抢らず，過去に飲酒習慣を持つ者が，なん らかの理由で飲酒を制限し「非飲酒群」に割り当てられ ている可能性を排除できない. しかしながら, 本研究に 扣いても先行研究と同様に,「多量飲酒群」と比較して 少量あるいは非飲酒群は, 統計学的に有意ではないもの の低い全がん死亡の相対危険度を示して抢り，飲酒習慣 をある程度正確に把握できているものと考えられる。ま た，ALDH2等のアルコール代謝関連遺伝子の多型が発 がんに影響を及ぼすことが報告されており ${ }^{28)}$ ，これらの 多型の分布が本研究の結果に交絡している可能性は否定 できない.しかしながら本研究においては対象者のアル コール代謝関連遺伝子の多型に関する調査を実施してお らず，この点に関しては今後の課題であると考えられ る。また, 本研究に打ける死因の把握は職場総務担当者 もしくは家族に対する電話聞き取り調查によって行って おり，正確に死因を把握できていない可能性がある。し かしながら，本研究は全がん死亡を対象としており特定 部位におけるがんを調査対象としていないことや，がん 死亡の有無に関する単純な確認であることからから誤分 類が発生する可能性は低いと考えられる。最後に, 本研 究に打ける全身持久力の測定は間接法を用いており，直 接法と比較して精度の低いことが課題としてあげられる が, Teräslinnaら ${ }^{29)}$ が本研究で用いた方法と同様の方法

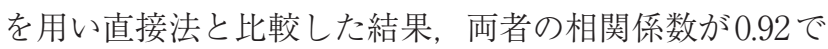
あることを報告している。したがって，本研究で用いた 全身持久力の評価方法は，対象者を基準值で 2 群に分類 する上では十分な精度を有していると考えられる。 な抏, 本研究の対象者は男性のみを対象としているため，女性 では結果が異なる可能性があり, 今後検討が必要な課題 である。

\section{結 論}

本研究は，全身持久力と飲酒習慣の組み合わせが全が ん死亡の予測因子のひとつになりうる可能性を示してい た，すなわち，全身持久力が「健康づくりのための身体 活動基準2013」における全身持久力の基準值を満たし, 飲酒を控えている日本人の男性労働者は全がん死亡のリ 
スクが他の群と比較して統計学的に低いことが確認され た。がん死亡を予防するためには，日常的な飲酒を避け るとともに，全身持久力を維持・向上させることが重要 であると考えられる。

\section{謝 辞}

東京ガス株式会社における本研究への参加者および安全 健康・福利室のスタッフの皆様に感謝いたします。

\section{引用文献}

1) World Health Organization. World Health Statistics 2012. http://apps.who.int/iris/bitstre am/10665/44844/1/9789241564441_eng.pdf. 2012.

2) Blair SN, Kohl HW, Paffenbarger RS, Clark DG, Cooper KH, Gibbons LW. Physical fitness and all-cause mortality. A prospective-study of healthy-men and women. JAMA 262: 2395-2401, 1989.

3) Byun W, Sui XM, Hebert JR, Church TS, Lee IM, Matthews CE, Blair SN. Cardiorespiratory fitness and risk of prostate cancer: findings from the Aerobics Center Longitudinal Study. Cancer Epidemiol 35: 59-65, 2011.

4) Evenson KR, Stevens J, Cai JW, Thomas R, Thomas O. The effect of cardiorespiratory fitness and obesity on cancer mortality in women and men. Med Sci Sports Exerc 35: 270-277, 2003.

5) Farrell SW, Cortese GM, LaMonte MJ, Blair SN. Cardiorespiratory fitness, different measures of adiposity, and cancer mortality in men. Obesity 15: 3140-3149, 2007.

6) Kampert JB, Blair SN, Barlow CE, Kohl HW. Physical activity, physical fitness, and all-cause and cancer mortality: A prospective study of men and women. Ann Epidemiol 6: 452-457, 1996.

7) Laukkanen JA, Pukkala E, Rauramaa R, Makikallio TH, Toriola AT, Kurl S. Cardiorespiratory fitness, lifestyle factors and cancer risk and mortality in Finnish men. Eur J Cancer 46: 355-363, 2010.

8) Lee CD, Blair SN. Cardiorespiratory fitness and smoking-related and total cancer mortality in men. Med Sci Sports Exerc 34: 735-739, 2002.

9) Oliveria SA, Kohl HW, Trichopoulos D, Blair SN. The association between cardiorespiratory fitness and prostate cancer. Med Sci Sports Exerc 28: 97-104, 1996.

10) Peel JB, Sui $X$, Matthews CE, Adams SA, Hebert JR, Hardin JW, Church TS, Blair SN. Cardiorespiratory fitness and digestive cancer mortality: findings from the Aerobics Center Longitudinal Study. Cancer Epidemiol Biomarkers 18: 1111-1117, 2009.

11) Sui XM, Lee DC, Matthews CE, Adams SA, Hebert JR, Church TS, Lee CD, Blair SN. Influence of cardiorespiratory fitness on lung cancer mortality. Med Sci Sports Exerc 42: 872-878, 2010.

12) Thompson AM, Church TS, Janssen I, Katzmarzyk PT, Earnest CP, Blair SN. Cardiorespiratory fitness as a predictor of cancer mortality among men with pre- diabetes and diabetes. Diabetes Care 31: 764-769, 2008.

13) Sawada SS, Muto T, Tanaka H, Lee IM, Paffenbarger RS, Shindo M, Blair SN. Cardiorespiratory fitness and cancer mortality in Japanese men: A prospective study. Med Sci Sports Exerc 35: 1546-1550, 2003.

14) Jin M, Cai S, Guo J, Zhu Y, Li M, Yu Y, Zhang S, Chen K. Alcohol drinking and all cancer mortality: a metaanalysis. Ann Oncol 24: 807-816, 2013.

15) Inoue $M$, Wakai $K$, Nagata $C$, Mizoue $T$, Tanaka $K$, Tsuji I, Tsugane S; Research Group for the Development, Evaluation of Cancer Prevention Strategies in Japan. Alcohol drinking and total cancer risk: an evaluation based on a systematic review of epidemiologic evidence among the Japanese population. Jpn J Clin Oncol 37: 692-700, 2007.

16) Sasazuki S, Inoue M, Iwasaki M, Sawada N, Shimazu T, Yamaji T, Tsugane S; JPHC Study Group. Combined impact of five lifestyle factors and subsequent risk of cancer: the Japan Public Health Center Study. Prev Med 54: 112-116, 2012.

17) Gallagher EJ, LeRoith D. Minireview: IGF, Insulin, and Cancer. Endocrinology 152: 2546-2551, 2011.

18) Henriksen EJ. Invited review: Effects of acute exercise and exercise training on insulin resistance. J Appl Physiol 93: 788-796, 2002.

19) Shah JH. Alcohol decreases insulin sensitivity in healthy subjects. Alcohol Alcohol 23: 103-109, 1988.

20) Astrand I. Aerobic work capacity in men and women with special reference to age. Acta Physiol Scand 49: 1-92, 1960.

21) Astrand PO, Ryhming I. A nomogram for calculation of aerobic capacity (physical fitness) from pulse rate during sub-maximal work. J Appl Physiol 7: 218-221, 1960.

22）厚生労働省運動基準・運動指針の改定に関する検討 会. 健康づくりのための身体活動基準 2013. http:// www.mhlw.go.jp/stf/houdou/2r9852000002xpleatt/2r9852000002xpqt.pdf. 2013.

23) Tsumura K, Hayashi T, Suematsu C, Endo G, Fujii S, Okada K. Daily alcohol consumption and the risk of type 2 diabetes in Japanese men: the Osaka Health Survey. Diabetes Care 22: 1432-1437, 1999.

24) Nakanishi N, Suzuki K, Tatara K. Alcohol consumption and risk for development of impaired fasting glucose or type 2 diabetes in middle-aged Japanese men. Diabetes Care 26: 48-54, 2003.

25) Inoue M, Tsugane $\mathrm{S}$, the JPHC Study Group. Impact of alcohol drinking on total cancer risk: data from a large-scale population-based cohort study in Japan. $\mathrm{Br}$ J Cancer 92: 182-185, 2005.

26) Facchini F, Chen YD, Reaven GM. Light-to-moderate alcohol intake is associated with enhanced insulin sensitivity. Diabetes Care 17: 115-119, 1994.

27) Blair SN, Kampert JB, KohlHW3rd, Barlow CE, Macera CA, Paffenbarger RS Jr, Gibbons LW. Influences of cardiorespiratory fitness and other precursors on cardiovascular disease and all-cause mortality in men and 
women. JAMA 276: 205-210, 1996.

28) Oze I, Matsuo K, Hosono S, Ito H, Kawase T, Watanabe M, Suzuki T, Hatooka S, Yatabe Y, Hasegawa Y, Shinoda M, Tajima K, Tanaka H. Comparison between self-reported facial flushing after alcohol consumption and ALDH2 Glu504Lys polymorphism for risk of upper aerodigestive tract cancer in a Japanese population. Cancer Sci 101: 1875-1880, 2010.

29) Teräslinna P, Ismail AH, Macleod DF. Nomogram by Astrand-Ryhming as a predictor of maximum oxygen intake. J App Physiol 21: 513-515, 1966. 